\title{
High methylation of the SEPT9 gene in Chinese colorectal cancer patients
}

\author{
X.L. Su ${ }^{1 *}$, Y.F. Wang ${ }^{2 *}$, S.J. Li $^{3}$, F. Zhang ${ }^{4}$ and H.W. Cui ${ }^{1}$ \\ ${ }^{1}$ Clinical Medical Research Center of the Affiliated Hospital, \\ Inner Mongolia Medical University, Hohhot, China \\ ${ }^{2}$ Department of Pathology, Inner Mongolia Medical University, Hohhot, China \\ ${ }^{3}$ Department of Pathology, Chifeng Hospital, Chifeng, China \\ ${ }^{4}$ Department of Pathology, Inner Mongolia People's Hospital, Hohhot, China \\ *These authors contributed equally to this study. \\ Corresponding author: X.L. Su \\ E-mail: xlsu2012@gmail.com
}

Genet. Mol. Res. 13 (2): 2513-2520 (2014)

Received May 10, 2013

Accepted September 23, 2013

Published January 17, 2014

DOI http://dx.doi.org/10.4238/2014.January.17.5

\begin{abstract}
Methylation of the septin 9 gene (SEPT9) occurs in higher frequency in colorectal cancer (CRC) compared to control samples, which suggests that SEPT9 methylation is a useful biomarker for screening CRC. However, the methylation status of SEPT9 in Chinese CRC patients is scarcely reported. In the present study, SEPT9 methylation was tested in CRC tissues obtained from a Chinese population and correlations with pathological characteristics were investigated. The methylation status of SEPT9 was detected using methylation-specific polymerase chain reaction (PCR)-denaturing high-performance liquid chromatography (MSP-DHPLC) in 234 colorectal tissues (172 cases, 62 controls). Samples were sequenced to confirm the results from MSP-DHPLC. The chi-squared test was used to analyze the correlation of SEPT9 gene methylation status and pathological characteristics in CRCs. SEPT9 gene methylation was detected in 152 of $172(88.4 \%)$ cases of verified CRC and in 4 of $62(6.5 \%)$ healthy controls $\left(\chi^{2}=137.62, \mathrm{P}<0.001\right)$. There was no association between the methylation status of SEPT9 and age, gender,
\end{abstract}


Duke's stage, TNM stage, differentiation, and site of cancer $(\mathrm{P}>0.05)$. Our results suggest that SEPT9 gene methylation is a valuable biomarker for screening CRC in the Chinese population.

Key words: SEPT9; Methylation; Colorectal cancer; Chinese population

\section{INTRODUCTION}

Colorectal cancer (CRC) is the third most common malignant tumor in males and the second most common in females worldwide. There were over 1.2 million new cancer cases and 608,700 estimated cancer deaths reported in 2008 (Jemal et al., 2011). The CRC incidence rates are rapidly increasing in a number of countries within Eastern Asia, including Japan and China (Center et al., 2009). The survival rate of colon cancer has increased over the past 20 years owing to early detection from increased screening and improved treatment. The fecal occult blood test (FOBT), flexible sigmoscope, and colonoscopy are common methods to screen early CRC (Cunningham et al., 2010). It is estimated that CRC deaths could be reduced by about $60 \%$ if patients are screened routinely (He and Efron, 2011). With the development of molecular biology and the availability of molecular markers, great progress has been made in screening CRC (Baylin et al., 2001; Creeden et al., 2011; Lind et al., 2011). The methylation of the septin (SEPT) 9 gene (SEPT9) is one of the molecular markers commonly used in detecting CRC (Feinberg, 2004; Lofton-Day et al., 2008; Warren et al., 2011).

Septins belong to a GTP binding protein family and currently consists of 14 members in mammals (Bourne et al., 1991; Leipe et al., 2002; Connolly et al., 2011). The association of septins with actin and tubulin are required in cytokinesis (Spiliotis et al., 2005; Kinoshita, 2006). Due to their essential role in cell division and polarity, it is not surprising that septins were also reported to be key players in tumorigenesis (Osaka et al., 1999; Garcia-Fernandez et al., 2010; Jia et al., 2010). SEPT9 has been found to act as an oncogene and tumor suppressor gene in different types of cancers. Moreover, SEPT9 was reported to fuse to the mix lineage leukemia (MLL) in leukemia, providing further evidence to support its oncogenic role (Saito et al., 2010; Santos et al., 2010). In hormone-regulated cancers, such as prostate, ovarian, and breast cancer, overexpression of SEPT9 is accompanied by upregulation of hypoxia-inducible factor $1 \alpha$ (HIF1 $\alpha$ ) (Zhong et al., 1999; Scott et al., 2005, 2006; Amir et al., 2009), which is probably regulated by estrogen receptor (ER) signaling (Amir et al., 2009). Loss of expression of SEPT9 has been reported in head and neck cancer (Bennett et al., 2008) and CRC (Grutzmann et al., 2008).

Studies have shown that SEPT9 methylation occurs in CRC and its detection from peripheral blood is feasible, whereas the frequency of SEPT9 methylation in control samples is low (deVos et al., 2009; Tänzer et al., 2010). This suggests that SEPT9 methylation is a useful biomarker for screening CRC. Consistent with gene methylation, the expression of SEPT9 was significantly reduced in CRC patients compared to healthy controls. The mRNA and protein levels of SEPT9 increased in HT29 cells after demethylation treatment (Tóth et al., 2011). Colorectal tumorigenesis is highly correlated with environmental factors (Hall and Crowe, 2011); therefore, the SEPT9 methylation status of CRC in the Chinese population may be different from that of other populations. However, studies on the SEPT9 methylation of CRC in the Chinese population are scarce (He et al., 2010), and the relationship between SEPT9 methylation and gender, differentiation level, and stage remains unclear. In the present 
study, we detected the methylation status of SEPT9 using methylation-specific polymerase chain reaction (PCR)-denaturing high-performance liquid chromatography (MSP-DHPLC) in CRC patients and healthy controls in Inner Mongolia, China. The association between CRC pathological characteristics and methylation of SEPT9 was also analyzed.

\section{MATERIAL AND METHODS}

\section{Subjects}

In total, 234 subjects were enrolled from the Affiliated Hospital of Inner Mongolia Medical College, including 172 colorectal cancer patients (106 males, 66 females; mean age $61.29 \pm 11.40$ years) and 62 healthy controls (26 males, 36 females; mean age $53.00 \pm 13.77$ years). Paraffin-embedded CRC tissues and peripheral blood from healthy controls were used in this study. Pathological diagnosis confirmed that cancer cells occupied $>70 \%$ in the CRC tissues used in this study. The clinicopathological characteristics of patients are shown in Table 1. Standard informed consent was obtained from all participating subjects according to the protocol reviewed and approved by the Ethical Committee of the Affiliated Hospital of Inner Mongolia Medical College.

\begin{tabular}{|c|c|c|c|c|c|}
\hline \multirow[t]{2}{*}{ Groups } & \multirow[t]{2}{*}{ Cases } & \multicolumn{2}{|c|}{ SEPT9 } & \multirow[t]{2}{*}{$\chi^{2}$} & \multirow[t]{2}{*}{ P value } \\
\hline & & Methylation & Unmethylation & & \\
\hline \multicolumn{6}{|l|}{ Gender } \\
\hline Male & 106 & 95 & 11 & 1.442 & 0.230 \\
\hline Female & 66 & 55 & 11 & & \\
\hline \multicolumn{6}{|l|}{ Age (year) } \\
\hline$<50$ & 26 & 20 & 6 & 5.169 & 0.160 \\
\hline $50-59$ & 38 & 36 & 2 & & \\
\hline $60-69$ & 50 & 42 & 8 & & \\
\hline$>70$ & 58 & 52 & 6 & & \\
\hline \multicolumn{6}{|c|}{ Differentiation } \\
\hline Moderate & 152 & 133 & 19 & 0.099 & 0.753 \\
\hline Well & 20 & 17 & 3 & & \\
\hline \multicolumn{6}{|l|}{ Site } \\
\hline Rectum & 102 & 90 & 12 & 0.237 & 0.627 \\
\hline Colon & 70 & 60 & 10 & & \\
\hline \multicolumn{6}{|l|}{ Dukes' stage } \\
\hline A & 87 & 78 & 9 & 0.944 & 0.331 \\
\hline B & 85 & 72 & 13 & & \\
\hline \multicolumn{6}{|l|}{ TNM stage } \\
\hline T1N0M0 & 62 & 55 & 7 & 1.274 & 0.529 \\
\hline T2N0M0 & 26 & 24 & 2 & & \\
\hline T3N0M0 & 84 & 71 & 13 & & \\
\hline
\end{tabular}

\section{DNA extraction and modification}

Ten pieces of $5 \mu \mathrm{m}$ paraffin sections were cut from each sample. The paraffin sections were then added into Eppendorf tubes with xylene, and were washed with ethanol three times. DNA was extracted using the QIAamp ${ }^{\circledR}$ DNA FFPE Tissue Kit (Qiagen, Germany). The purity and concentration of DNA were analyzed with agarose gel electrophoresis and a UV spectro- 
photometer. The Whole Blood Genomic DNA Extraction Kit (TIANGEN, Beijing, China) was used to extract genomic DNA from the peripheral blood of healthy controls. DNA with treatment of enzyme Sss was used as the positive control, whereas DNA without treatment of enzyme Sss was used as the negative control. Sulfurous acid salt treatment was performed using the EZ DNA Methylation Gold Kit (Zymo Research, CA, USA). DNA was eluted in $30 \mu \mathrm{L}$ elution buffer.

\section{Amplification of SEPT9}

Methylation-specific PCR primers were designed according to the GenBank NG_011683 sequence. The SEPT9-M primers were forward 5'-TCCGAAATAATCCAACT-3' and reverse 5'-CGTAGGGTTCGGGTTTCGT-3', and the SEPT9-U primers were forward 5'-GTGTAGTTGGATGGGATTATT-3'andreverse5'-CCATCTCCCCTCAACACACTCCCA-3'. HotStarTaq DNA polymerase (QIAGEN) was used in DNA amplification. A touchdown PCR protocol was used for amplification of SEPT9 under the following program: initial denaturation at $95^{\circ} \mathrm{C}$ for $15 \mathrm{~min}$, followed by 40 cycles of denaturation at $95^{\circ} \mathrm{C}$ for $30 \mathrm{~s}$, annealing at $64^{\circ} \mathrm{C}$ for $30 \mathrm{~s}$, extension at $72^{\circ} \mathrm{C}$ for $30 \mathrm{~s}$, and a final extension at $72^{\circ} \mathrm{C}$ for $10 \mathrm{~min}$. DNA from peripheral blood lymphocytes (PBL) of the healthy controls with treatment of enzyme Sss were used as methylated positive controls. Distilled water was used as the template for the negative control. PCR products $(150 \mathrm{bp})$ were separated by $2 \%$ agarose gel electrophoresis and were stained with ethidium bromide. The gel was photographed using the UV Gel Documentation System.

\section{DHPLC analysis}

The amplification products were analyzed using DHPLC with the following steps: equal amounts amplification products of SEPT9-M PCR and SEPT9-U PCR were mixed and $5 \mu \mathrm{L}$ mixture was used for further analysis. The PCR products were separated by a DNASep ${ }^{\circledR}$ analytical column (Transgenomic, Inc.) and were analyzed by DHPLC on the WAVE ${ }^{\mathrm{TM}}$ DNA Fragment Analysis System. The analytical procedure was DS Multiple Fragments and the 100150 -bp fragments were analyzed at $50^{\circ} \mathrm{C}$ at a $0.9 \mathrm{~mL} / \mathrm{min}$ flow rate, and were detected by UV wave at $260 \mathrm{~nm}$. The results were analyzed using the Navigator software.

\section{Sequencing}

To confirm the gene methylation status from the DHPLC analysis, we performed sequencing in randomly selected samples. The primers for sequencing were SEPT9-M forward 5'-TATTAGTTATTATGTCGGATTTCGC-3' and reverse 5'-GCCTAAATTAAAAATCCCGT C-3', and SEPT9-U forward 5'-ATTAGTTATTATGTTGGATTTTGTGG-3' and reverse 5'-AAAACACCTAAATTAAAAATCCCATC-3'. DNA sequences were verified by direct sequencing (ABI Prism 3700 DNA analyzer 377; Applied Biosystems, Foster City, CA, USA).

\section{Statistical analysis}

Statistical analysis was performed with the SPSS 13.0 software. Pathological characteristics and differences in SEPT9 methylation between the CRC patients and controls were compared using the Pearson chi-squared test. 


\section{RESULTS}

The sensitivity of detecting the methylated SEPT9 gene was analyzed by MSP-DHPLC to identify the minimum detectable amount of cancer cells. Positive controls and negative controls were mixed proportionally. The contents of positive controls were 50,25, 10, and $1 \%$. The sensitivity was determined to be at least $1 \%$ (Figure 1A). Subsequently, we detected the methylation statuses of SEPT9 in all samples using MSP-DHPLC (Figure 1B). Samples showing a peak at the same time as the positive control in DHPLC were defined as positive, and were otherwise defined as negative.

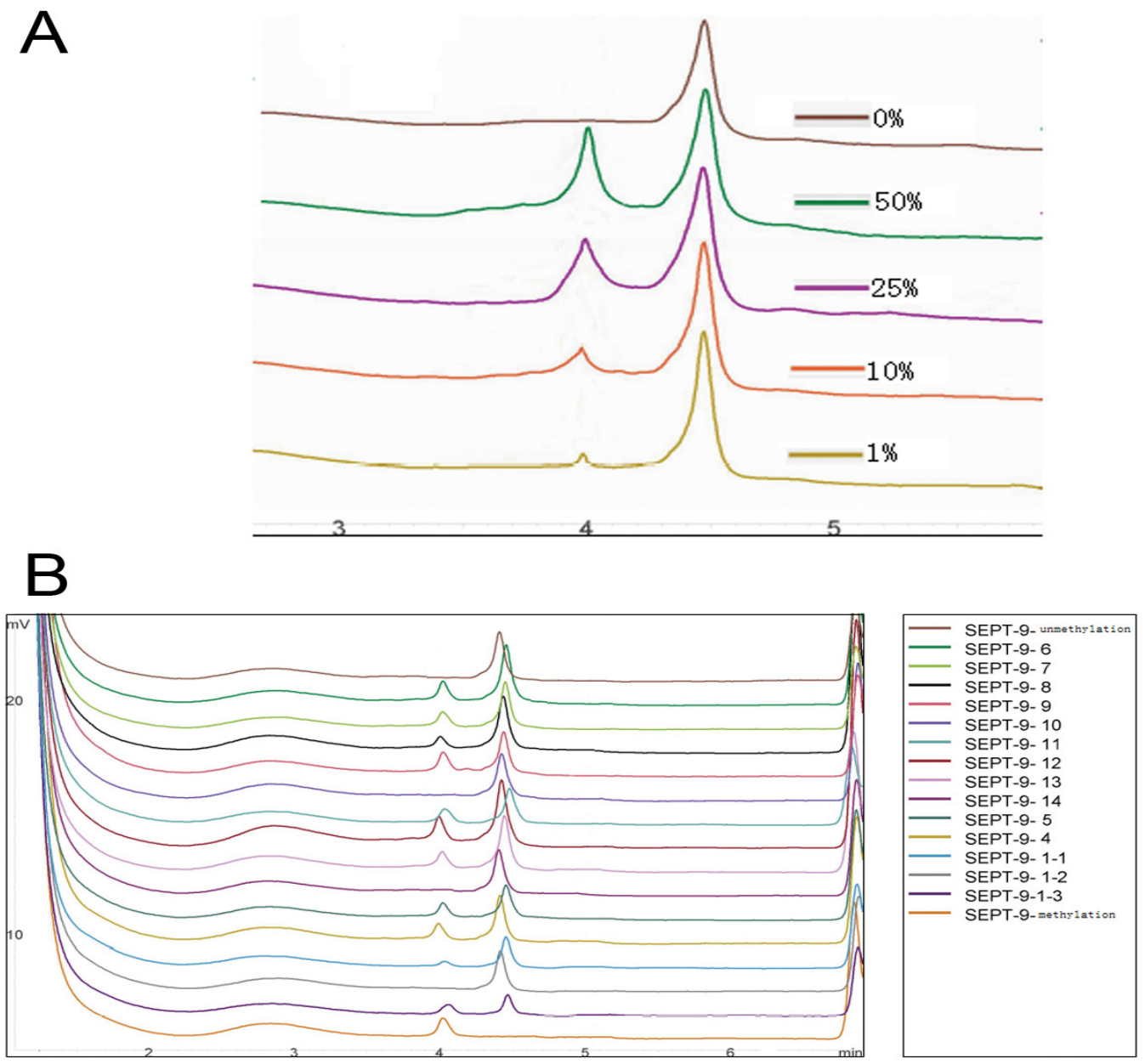

Figure 1. A. Assessment of sensitivity of MSP-DHPLC. Different concentrations (50, 25, 10, and 1\%) of positive controls and negative control $(0 \%$, unmethylation) were used. B. Image of methylated SEPT9 gene detected using MSP-DHPLC in some samples. SEPT-9-unmethylation = unmethylated control. SEPT-9-methylation = methylated control. SEPT-9-number $=$ number of samples involved in this study. 
Methylation of SEPT9 was identified in 152 out of 172 (88.4\%) CRC samples, whereas it was identified in only 4 out of $62(6.5 \%)$ control samples. There was a significant difference in the methylation status of SEPT9 between cases and controls $\left(\chi^{2}=137.62, \mathrm{P}<0.001\right.$; Table 2$)$.

Table 2. Distribution of methylation of SEPT9 gene in CRC patients and controls.
\begin{tabular}{lcccc}
\hline Groups & \multicolumn{3}{c}{} & SEPT 9 \\
& Methylation & Unmethylation & \multirow{2}{*}{ P value } \\
\hline Cases & $152(88.4)$ & $20(11.6 \%)$ & 137.62 & $<0.001$ \\
Controls & $4(6.5 \%)$ & $58(93.5 \%)$ & & \\
\hline
\end{tabular}

Furthermore, we analyzed the correlation between the methylation status of SEPT9 and gender, age, Duke's stage, TNM stage, differentiation, and site using the chi-squared test. There was no significant difference between any of the groups $(\mathrm{P}>0.05$, Table 1$)$. To confirm the results of the methylation status of SEPT9 from the DHPLC analysis, we sequenced the MSP-PCR products from randomly selected samples. The sequencing results were consistent with the results from DHPLC analysis.

\section{DISCUSSION}

MSP-DHPLC is a new assay that is currently used in clinics for the detection of mutations and methylations in China. The test is easy to perform, with high sensitivity and specificity (Divine et al., 2006). In our study, the frequency of SEPT9 methylation was significantly different between CRC cases and controls $\left(88.4\right.$ vs $\left.6.5 \%, \chi^{2}=137.62, \mathrm{P}<0.001\right)$.

The proportion of methylated SEPT 9 genes in CRC patients is $70-80 \%$. The sensitivity and specificity of SEPT9 methylation for detecting CRC in clinical samples is 88.4 and $93.5 \%$, respectively. Therefore, the methylation of SEPT9 is considered to be a specific biomarker of CRC (Grutzmann et al., 2008; deVos et al., 2009; Warren et al., 2011). The proportion of methylated SEPT 9 genes in our CRC patients was higher $(88.4 \%)$ than that observed in previous studies (deVos et al., 2009; Tänzer et al., 2010), and is likely correlated with the pathological diagnosis of patients. Furthermore, MSP with at least $1 \%$ detection sensitization was employed in this study. Whether the MSP method is correlated with experimental results is worth further investigation.

In the present study, we performed a correlation analysis of the methylation of SEPT9 and pathological characteristics of CRC samples in Inner Mongolia of China. Our results showed that the methylation status of SEPT9 was not associated with age, gender, Duke's stage, TNM stage, differentiation, or site. It was reported that the proportion of methylated SEPT9 genes increased with the progression of CRC (deVos et al., 2009; Warren et al., 2011), whereas in our study, the proportion of methylated SEPT9 was similar between well (17/20, $85 \%)$ and moderately differentiated (133/152, 87.5\%) CRC cases. However, this result might be biased by the larger number of moderately differentiated CRC cases in this study. Furthermore, there was no metastasis observed in the CRC samples (Duke's stage and TNM stage from Table 1); therefore, whether methylation of SEPT9 is involved in the metastasis of CRC needs further study in larger samples including cases of advanced CRC.

The Inner Mongolia region belongs to the alpine region where beef and mutton have served as the staple food with relatively less vegetables and fruits, and alcohol consumption is 
customary of local residents. Further investigation is needed to determine the influence of environment and lifestyle on CRC. Moreover, the size of the sample of the present study is quite small; therefore, increasing the sample size is required to confirm these results in future studies.

In conclusion, our results indicated that the methylation status of SEPT9 is a reliable index for screening CRC. Furthermore, the methylation of SEPT9 detected by MSP-DHPLC is also a useful biomarker in a clinical laboratory setting. Meanwhile, the development of SEPT9 methylation-specific drugs might be a new therapeutic approach for CRC.

\section{ACKNOWLEDGMENTS}

Research supported by the National Natural Science Foundation of China (\#81160254). We thank Dr. Yaguang Xi for critical revision of the manuscript.

\section{REFERENCES}

Amir S, Wang R, Simons JW and Mabjeesh NJ (2009). SEPT9_v1 up-regulates hypoxia-inducible factor 1 by preventing its RACK1-mediated degradation. J. Biol. Chem. 284: 11142-11151.

Baylin SB, Esteller M, Rountree MR, Bachman KE, et al. (2001). Aberrant patterns of DNA methylation, chromatin formation and gene expression in cancer. Hum. Mol. Genet. 10: 687-692.

Bennett KL, Karpenko M, Lin MT, Claus R, et al. (2008). Frequently methylated tumor suppressor genes in head and neck squamous cell carcinoma. Cancer Res. 68: 4494-4499.

Bourne HR, Sanders DA and McCormick F (1991). The GTPase superfamily: conserved structure and molecular mechanism. Nature 349: 117-127.

Center MM, Jemal A and Ward E (2009). International trends in colorectal cancer incidence rates. Cancer Epidemiol. Biomarkers Prev. 18: 1688-1694.

Connolly D, Abdesselam I, Verdier-Pinard P and Montagna C (2011). Septin roles in tumorigenesis. Biol. Chem 392: 725-738.

Creeden J, Junker F, Vogel-Ziebolz S and Rex D (2011). Serum tests for colorectal cancer screening. Mol. Diagn. Ther. 15: $129-141$.

Cunningham D, Atkin W, Lenz HJ, Lynch HT, et al. (2010). Colorectal cancer. Lancet 375: 1030-1047.

deVos T, Tetzner R, Model F, Weiss G, et al. (2009). Circulating methylated SEPT9 DNA in plasma is a biomarker for colorectal cancer. Clin. Chem. 55: 1337-1346.

Divine KK, Liechty KC, Crume KC and Belinsky SA (2006). Nested multigene MSP/DHPLC method for analyzing promoter hypermethylation status in clinical samples. Biotechniques 40: 40, 42, 44.

Feinberg AP (2004). The epigenetics of cancer etiology. Semin. Cancer Biol. 14: 427-432.

Garcia-Fernandez M, Kissel H, Brown S, Gorenc T, et al. (2010). Sept4/ARTS is required for stem cell apoptosis and tumor suppression. Genes Dev. 24: 2282-2293.

Grutzmann R, Molnar B, Pilarsky C, Habermann JK, et al. (2008). Sensitive detection of colorectal cancer in peripheral blood by septin 9 DNA methylation assay. PLoS One 3: e3759.

Hall EH and Crowe SE (2011). Environmental and lifestyle influences on disorders of the large and small intestine: implications for treatment. Dig. Dis. 29: 249-254.

He J and Efron JE (2011). Screening for colorectal cancer. Adv. Surg. 45: 31-44.

He Q, Chen HY, Bai EQ, Luo YX, et al. (2010). Development of a multiplex MethyLight assay for the detection of multigene methylation in human colorectal cancer. Cancer Genet. Cytogenet. 202: 1-10.

Jemal A, Bray F, Center MM, Ferlay J, et al. (2011). Global cancer statistics. CA Cancer J. Clin. 61: 69-90.

Jia ZF, Huang Q, Kang CS, Yang WD, et al. (2010). Overexpression of septin 7 suppresses glioma cell growth. $J$. Neurooncol. 98: 329-340.

Kinoshita M (2006). Diversity of septin scaffolds. Curr. Opin. Cell Biol. 18: 54-60.

Leipe DD, Wolf YI, Koonin EV and Aravind L (2002). Classification and evolution of P-loop GTPases and related ATPases. J. Mol. Biol. 317: 41-72.

Lind GE, Danielsen SA, Ahlquist T, Merok MA, et al. (2011). Identification of an epigenetic biomarker panel with high sensitivity and specificity for colorectal cancer and adenomas. Mol. Cancer 10: 85 . 
Lofton-Day C, Model F, Devos T, Tetzner R, et al. (2008). DNA methylation biomarkers for blood-based colorectal cancer screening. Clin. Chem. 54: 414-423.

Osaka M, Rowley JD and Zeleznik-Le NJ (1999). MSF (MLL septin-like fusion), a fusion partner gene of MLL, in a therapy-related acute myeloid leukemia with a t(11;17) (q23;q25). Proc. Natl. Acad. Sci. U. S. A. 96: 6428-6433.

Saito H, Otsubo K, Kakimoto A, Komatsu N, et al. (2010). Emergence of two unrelated clones in acute myeloid leukemia with MLL-SEPT9 fusion transcript. Cancer Genet. Cytogenet. 201: 111-115.

Santos J, Cerveira N, Bizarro S, Ribeiro FR, et al. (2010). Expression pattern of the septin gene family in acute myeloid leukemias with and without MLL-SEPT fusion genes. Leuk. Res. 34: 615-621.

Scott M, Hyland PL, McGregor G, Hillan KJ, et al. (2005). Multimodality expression profiling shows SEPT9 to be overexpressed in a wide range of human tumours. Oncogene 24: 4688-4700.

Scott M, McCluggage WG, Hillan KJ, Hall PA, et al. (2006). Altered patterns of transcription of the septin gene, SEPT9, in ovarian tumorigenesis. Int. J. Cancer 118: 1325-1329.

Spiliotis ET, Kinoshita M and Nelson WJ (2005). A mitotic septin scaffold required for Mammalian chromosome congression and segregation. Science 307: 1781-1785.

Tänzer M, Balluff B, Distler J, Hale K, et al. (2010). Performance of epigenetic markers SEPT9 and ALX4 in plasma for detection of colorectal precancerous lesions. PLoS One 5: e9061.

Tóth K, Galamb O, Spisak S, Wichmann B, et al. (2011). The influence of methylated septin 9 gene on RNA and protein level in colorectal cancer. Pathol. Oncol. Res. 17: 503-509.

Warren JD, Xiong W, Bunker AM, Vaughn CP, et al. (2011). Septin 9 methylated DNA is a sensitive and specific blood test for colorectal cancer. BMC Med. 9: 133.

Zhong H, De Marzo AM, Laughner E, Lim M, et al. (1999). Overexpression of hypoxia-inducible factor 1alpha in common human cancers and their metastases. Cancer Res. 59: 5830-5835. 